Asia-Pacific Journal of Management and

Technology

Online ISSN: 2652-6840

www.ajmt.org

Original Article

\title{
Socio-Economic Impact of Select Infrastructure Projects - A Study Based on Howrah Bridge, West Bengal, India
}

\author{
Sayan Basu*, Pranam Dhar \\ Department of Commerce \& Management, West Bengal State University, Barasat, North 24 Pgs. West Bengal, \\ India.
}

${ }^{*}$ Correspondence E-mail: basusayan19@gmail.com

\begin{abstract}
In India the present economy must be reconstructed. For thatwe need innovative infrastructure such as sanitation, drivable roads and potable water. Formerly, many governments used to finance for infrastructure projects by supportigthese projects. But this support is no longer sustainable in developed countries due to the emerging deficits and sovereign debt. Additionally, infrastructure stimulus packages will reasonably reverse as governments look to bring their financial condition under control. The present research will try to evaluate the socio-economic development by looking at opportunities for economic productivity, socio-economic capability to enhance a sustainable and healthy life with equal economic distribution. The tools used here are Exploratory Factor Analysis mainly, using Principal Component Analysis with Varimax Method of rotation. The study has been done on our heritage bridge i.e Howrah Bridge and it has been sub-divided into various sub-sections based on a structured questionnaire.
\end{abstract}

Keywords: - Infrastructure Projects, Socio-Economic Development, Howrah Bridge, Equal Economic Distribution, Exploratory Factor Analysis

\section{Introduction}

Infrastructure construction is a capitalintensive process with high initial costs and low operating costs. Since the construction time for such ventures is always much longer, it necessitates long-term financial support Mor \& Sehrawat (2006). Infrastructure projects are characterised by non-recourse or minimal recourse funding, which means that lenders may only be reimbursed from project revenues. To reconstruct the economy, meanwhile, we need innovative infrastructure such as sanitation, drivable roads and potable water immediately. In the past, many governments - used to finance for infrastructure projects - provided cash and/or guarantees to fund infrastructure projects. However, due to emerging deficits and sovereign debt, this funding is no longer sustainable in developing countries. Furthermore, as governments seek to regain control of their finances, infrastructure stimulus packages will likely to reverse. The World Bank, export credit agencies, and other multilaterals, as well as state-owned infrastructure banks, will continue to play key roles in infrastructure financing. Specialist funds may emerge, and pension funds and sovereign wealth funds will increasingly seek direct investments in infrastructure projects and businesses.

In the developing countries huge money is likely to be spent on the operation and maintenance of existing facilities Montgomery \& Elimelech (2007). If the government associations can provide stability and specialised transactional capability to the 
private developers then Public-private partnerships (PPPs) would gain impulse for new infrastructure.

Howrah Bridge is an iconic landmark of Kolkata, is a massive steel structure that is one of the world's longest cantilever bridges of its kind. It links Howrah and Kolkata across the Hooghly River and is also known as Rabindra Setu. It is also one of the busiest bridge, with over 100,000 cars and countless pedestrians passing through on a regular basis. The glory, of the bridge can be felt in a ferry ride between Kolkata and Howrah, starting from Launch Ghat.

At the time of its completion, the Howrah Bridge was the third-longest cantilever bridge in the world, but it is now the sixth-longest. Rabindra Setu, named after Nobel Laureate Rabindranath Tagore, was renamed on June 14, 1965. It is 1500 feet long and 71 feet wide, spanning the Hooghly River. There are 8 lanes of strand path, as well as for bicycles and pedestrians. The fact that this bridge was constructed without a single nut or bolt and is held together by rivets is what sets it apart.

\section{Review of Literature:}

Mor \&Sehrawat (2006) in their study stated that Infrastructural growth is very much important to meet the growth requirements of the country. Specialist funds may emerge, and pension funds and sovereign wealth funds will increasingly seek direct investments in infrastructure projects and businesses.

Inderst (2009) stated that as the need for investment in infrastructure will continue to grow in future, private sector financing for infrastructure projects will be developing all around the world. Such investments span a wide range of programmes, ranging from economic infrastructure like transportation to social infrastructure like hospitals, and they require a variety of financing options.

Ehlers (2014) stated that the major problem is to supply properly planned and structured projects into available finance related to infrastructure. Without a proper strategy in place, the fixed costs of developing this experience will quickly become prohibitively expensive for potential developers.Since project returns are only created over time, the emphasis should shift to the operational aspects of infrastructure rather than just its development.

Estache (2004) analysed the latest economic policies on emerging challenges for infrastructure and opined that it is affecting the poor in a variety of developed countries. So the key goal is to recognise the obstacles that foreign countries, and in particular donation providers, will face in the coming years.

Saravanan (2008) stated that though PPPs have evolved from the project finance space, they are quite different in terms of complex contractual agreements, governance and accountability measures. The empirical evidences across the globe showed that PPPs have the potential to provide infrastructure at more reasonable prices than comparative delivery through the public sector. The relative strengths and limitations of each PPP scheme should be weighed in order to ensure value for money.

As Basel 3 makes its way through the markets, the debt-control environment will continue to change. The regulations have the potential to increase the price of long-term debt while decreasing the supply. So the present study analyses the Howrah Bridge infrastructure in Kolkata, the revenues earned and focuses on its social and economic impact.

\section{Research Methods:}

For this analysis, both quantitative and qualitative research approaches were used. To be more descriptive, ethnographic methods, grounded analysis, and focus group methods were used in the study, with the evolving socio-economic conditions of the sample respondents taken into account, in addition to an interview with the aid of a standardised questionnaire. Based on the Interview Schedule, structured and conducted, proper interviewing methods were used. Due to the pandemic and long-term lockdown in the study area, a Google form was also used to collect data.

Primary Data: The reliability and internal consistency test of the questionnaire is carried out by using Cronbach's Alpha Test. According to Cronbach (1984), this test is the 
most used test for reliability in social science research. The Cornbach's Alpha estimate is denoted by the Greek letter a (Keith, 2018). The number of the item scores is often used to reflect the scale score for the target build (Heo et al., 2015).

\section{Results \& Discussion:}

Gender of the Respondents: Out of the total respondents of 130 , for this particular bridge, $28.5 \%$ are males and $71.5 \%$ are females.

Educational qualification of the Respondents: Majority of the respondents are below 10th Standard.

Monthly Incomes of the Respondents: Majority of the respondents earn below INR 5000 per month.

Residential Areas of the Respondents: Out of 130 respondents, $72.3 \%$ belongs to the City areas, $16.9 \%$ belongs to the Town areas and only $10.8 \%$ belongs to the Village areas.

Climatic condition of the Study Area: After the formation and usage of the Howrah Bridge, no major changes came out in the climatic conditions of the nearby areas of the bridge.

Land Use of the Study Area: Due to the formation and usage of the Howrah Bridge, Land usage became proper and useful accotding to maximum of the respondents.

Air Quality of the Study Area: After the formation and usage of the Howrah Bridge, Air Quality remained normal; no major changes came out there.

Soil Quality of the Study Area: About 44.6\% and $17.7 \%$ responded that the Soil Quality in the nearby areas of the bridge has became unhygienic and highly unhygienic respectively.So it can be concluded that, after the formation and usage of the Howrah Bridge, Soil quality in the nearby areas of the bridge has become unhygienic.

Noise Level of the Study Area: After the formation and usage of the Howrah Bridge, Noise Levels remained normal; no major changes came out there.

Vibration in the Study Area: After the formation and usage of the Howrah Bridge, majority of the respondents said that Vibration Levels remained normal; no major changes came out there.

Past Emanation of the Study Area: After the formation and usage of the Howrah Bridge, majority of the respondents said that Past Emanation remained normal; no major changes came out there.

Traffic Jam in the Study Area: After the formation and usage of the Howrah Bridge, majority of the respondents said that the traffic jam remained normal.

Solid Waste Disposal: After the formation \& usage of the Howrah Bridge, majority of the respondents said that the solid waste disposal are normal.

Drainage in the Study Area: After the formation and usage of the Howrah Bridge, majority of the respondents are happy with drainage system of the nearby areas of the bridge.

Conveyance in the Study Area: After the formation and usage of the Howrah Bridge, majority of the respondents are happy with the conveyance facilities they are receiving from the bridge.

So the significance of Howrah Bridge can be clearly understood in relation to Kolkata and its adjacent areas(Bateson et al., 1947). Communication is a pillar on which Kolkata and Howrah are built, so it is critical for the city to work efficiently. They beautify the Kolkata skyline and draw a large number of visitors to the area, which keeps it afloat economically and commercially. As a result, it is critical to comprehend the bridge's specifications and ensure that it continues to support the region's population. It is a structural wonder and the epitome of architectural and design uniqueness(Frangopol\& Liu, 2007).

\section{Conclusion:}

From the present study it is evident that the amount of construction work required to erect this monumental structure is worth researching, and the builders faced significant engineering challenges. As a result of the engineering analysis of the Howrah Bridge, engineers will go on to construct similar structures all over the world. The materials needed were significantly less than those 
required for the Howrah Bridge, making it an ideal model for other cities looking to build bridges to accommodate large numbers of vehicles. As a result, if we consider all of these factors, it is worthwhile to learn more about these bridges in depth, with this topic serving as a good example.

\section{Acknowledgments:}

The author is thankful to the institutional authority for completion of the work.

\section{Conflicts of Interest:}

The author declares that the research review was conducted in the absence of any commercial or economic associations that could be construed as a potential conflict of interest.

\section{References:}

Bateson, E., Howorth, G. E., Fuller, F. M., Hamilton, J., Turner, J., Measor, E., \& Ward, A. (1947). Discussion. The New Howrah Bridge, Calcutta: Design of The Structure, Foundations and Approaches. Construction. Papers 5612 \& 5601.Journal of the Institution of Civil Engineers, 28(7), 237-257.

Cronbach, L. J. (1949). Essentials of psychological testing. Harper.

Ehlers, T. (2014). Understanding the challenges for infrastructure finance.Retirived from : https://www.bis.org/publ/work454.pdf

Estache, A. (2004). Emerging infrastructure policy issues in developing countries: A survey of the recent economic literature. The World Bank.
Frangopol, D. M., \& Liu, M. (2007). Maintenance and Management of Civil Infrastructure Based on Condition, Safety, Optimization, And Life-Cycle Cost. Structure and Infrastructure Engineering, 3(1), 29-41.

Heo, M., Kim, N. \& Faith, S. M. (2015). Statistical power as a function of Cronbach alpha of instrument questionnaire items. BMC Medical Research Methodology. 15:86. DOI 10.1186/s12874-015-0070-6

Inderst, G. (2009). Pension fund investment in infrastructure. doi:10.1787/227416754242. www.oecd.org/daf/fin/wp. 32

Keith, S.T. (2018). The Use of Cronbach's Alpha When Developing and Reporting Research Instruments in Science Education. Res Sci Educ. 48. 1273-1296. DOI 10.1007/s11165-016-9602-2

Montgomery, M. A., \& Elimelech, M. (2007). Water and Sanitation in Developing Countries: Including Health in The Equation. Environmental Science \& Technology, 41(1), 17-24.

Mor, N. \&Sehrawat, S. (2006). Sources of Infrastructure Finance, Working Paper Series of The Institute for Financial Management and Research centre For Development Finance

Saravanan, P. (2008). Financing Sustainable Infrastructure-Assessing the Risks in Public Private Partnership Models. The Chartered Secretary Journal, November.. http://ssrn.com/abstract=1520939 